\title{
SOMETHING OUT OF NOTHING? NEOCLASSICAL GROWTH AND THE 'TRIVIAL' STEADY STATE
}

\author{
HENDRIK HAKENES \\ ANDREAS IRMEN
}

\author{
CESIFO WORKING PAPER NO. 1671 \\ CATEGORY 5: Fiscal Policy, MACROECONOMICS AND GROWTH \\ FEBRUARY 2006
}

An electronic version of the paper may be downloaded

- from the SSRN website:

www.SSRN.com

- from the CESifo website:

www.CESifo-group.de 


\title{
SOMETHING OUT OF NOTHING? NEOCLASSICAL GROWTH AND THE 'TRIVIAL' STEADY STATE
}

\begin{abstract}
A common perception about the neoclassical growth model is that an economy devoid of capital cannot evolve to strictly positive levels of output if capital is essential. We challenge this view by positing a broad class of production functions, encompassing the neoclassical production function, that - surprisingly - show that a take-off is possible even though the initial capital stock is zero and capital is essential. Since the marginal product of capital is initially infinite, the "trivial" steady state becomes so unstable that the solution to the equation of motion involves the possibility of a take-off. When it happens, the take-off is spontaneous: there is no causality, not even randomness.
\end{abstract}

JEL Code: O11, O14, O41, N6.

Keywords: capital accumulation, neoclassical growth model.

Hendrik Hakenes
Carlson School of Management
University of Minnesota
Finance Department
3-109 CarlSMgmt, 321
$19^{\text {th }}$ Ave S
Minneapolis MN 55455
USA
hakenes@coll.mpg.de

Hendrik Hakenes niversity of Minnesota

Finance Department $19^{\text {th }}$ Ave S

USA

hakenes@coll.mpg.de 


\section{Introduction}

Most specifications of the neoclassical growth model of Solow (1956) and Swan (1956) exhibit an unstable state with zero capital, often referred to as the trivial steady state. Intuitively, it obtains in a closed economy devoid of capital if capital is essential to generate income. Based on this intuition, one is inclined to draw the conclusion that the evolution of capital must be at a point of rest. For instance, Romer (2006, p. 16) writes, "If $k$ [the capital intensity per unit of efficient labor] is initially zero, it remains there". This assessment may be based on Solow (1956, p. 70), who notes, "If $K=0, r=0$ [the capital intensity] and the system can't get started; with no capital there is no output and hence no accumulation. But this equilibrium is unstable: the slightest windfall capital accumulation will start the system off ...". Our analysis challenges these assessments. We show that a neoclassical economy may take off even though the initial capital stock is zero and capital is essential, i. e., the system can get started, even without a slight windfall capital. When this happens, the ignition of the process of capital accumulation is spontaneous: there is no immediate cause.

Our finding is based on a careful analysis of the instability associated with the trivial steady state. We show for a broad class of aggregate production functions (including the neoclassical production function) that the solution to the equation of motion for capital cannot be unique when capital is zero. Two assumptions, the essentiality of capital and the Inada condition for capital (Inada (1963)), imply this result. Together they impose opposing forces on the accumulation process when there is zero capital. On the one hand, since capital is essential, there is nothing to invest; on the other hand, due to the Inada condition, the contribution of a marginal increment in capital to the change in capital is infinite. The behavior of the trajectory for capital is then indeterminate. Depending on which of these two forces "gets the upper hand", the economy may either remain without capital, or take off. The purpose of the following sections is to clarify the technical and intuitive 
underpinnings of this somewhat counterintuitive phenomenon. ${ }^{1}$

Section 2 develops our main result for a (neo)classical economy that is equipped with a Cobb-Douglas production function. We link our finding to the lack of Lipschitz continuity in the equation of motion. This property allows for multiple solutions. In Section 3, we extend the setting to more general production functions and develop our main theorem. Here, we identify the tension between the essentiality of capital and the Inada condition as the driving force behind the spontaneous take-off. Section 4 concludes.

\section{Neoclassical Growth under Cobb-Douglas}

Consider a closed economy in continuous time, equipped with the aggregate production function

$$
Y(t)=F(K(t), L(t))=A K(t)^{\alpha} L(t)^{\beta} T^{1-\alpha-\beta},
$$

where $A>0$ is total factor productivity, $K(t) \geq 0$ the capital stock at time $t$, $L(t)=e^{n t}$ the employed population at $t$ (growing at rate $n \geq 0$ ), and $T$ the available land. ${ }^{2}$ Assume that $\alpha, \beta \in(0 ; 1)$. If, in addition, $0<\alpha+\beta<1$, then this production function (i) exhibits constant returns to scale, (ii) it has positive and diminishing returns, (iii) it satisfies the Inada conditions, and (iv) all of its inputs are essential. Swan (1956) calls this a classical case as opposed to an unclassical case for which he stipulates $\alpha+\beta=1$. In the latter case, the amount of available

\footnotetext{
${ }^{1}$ It is worth noting that several recent growth models, including Mankiw, Romer, and Weil (1992) and Kremer (1993), exhibit the possibility of a spontaneous take-off. A detailed discussion is available from the authors upon request. Hakenes and Irmen (2005) show that such phenomenon also arises in dual economies in the spirit of Harris and Todaro (1970).

${ }^{2}$ To allow for exogenous technological progress, one may simply replace $n$ by $\tilde{n}=n+x$, where $x>0$ is the growth rate of some factor multiplied with $L(t)$. All results of this paper extend to settings with exogenous labor-augmenting technical progress.
} 
land has no influence upon aggregate output, and the four properties hold with respect to capital and labor, i. e. the production function is neoclassical in the sense of Barro and Sala-í-Martin (2004, pp. 26-28).

The equation of motion for the capital stock is

$$
\dot{K}(t)=s Y(t)-\delta K(t)
$$

where $s \in(0 ; 1)$ is the savings rate and $\delta \geq 0$ the instantaneous depreciation rate. Without loss of generality we normalize and set $T=1$. Then, the evolution of capital becomes

$$
\dot{K}(t)=s A K(t)^{\alpha} e^{n \beta t}-\delta K(t)
$$

Since our focus is on the trivial solution, we restrict attention to the initial value problem, with $K\left(t_{c}\right)=0$ for some time $t_{c}$. This problem has two algebraic solutions,

$$
\begin{aligned}
& K_{1}(t)=\left(A \frac{s(1-\alpha)}{n \beta+\delta(1-\alpha)}\left(e^{n \beta t}-e^{n \beta t_{c}} e^{-(1-\alpha) \delta\left(t-t_{c}\right)}\right)\right)^{\frac{1}{1-\alpha}}, \quad \text { and } \\
& K_{2}(t)=0 \text { for all } t .
\end{aligned}
$$

In addition, piece-wise combinations of $K_{1}$ and $K_{2}$ qualify as a solution as long as these are continuous and differentiable at the joint. The solution $K_{1}(t)$ obtains because (3) is a Bernoulli equation that can be solved by appropriate substitution (see, e.g. Gandolfo $\left(1997\right.$, p. 436)). ${ }^{3}$ We refer to $K_{2}(t)$ as the trivial solution.

Observe that $K_{1}\left(t_{c}\right)=0$. For $t<t_{c}, K_{1}(t)$ may either become positive or negative. In the former case, the implication is $\dot{K}_{1}(t)<0$, which is contradictory to (3): when the capital stock is rather small, it cannot shrink since the additions to the capital stock exceed depreciation. In the latter case, $K(t) \geq 0$ is violated. Hence, $K_{1}(t)$ can only be part of a solution for $t \geq t_{c}$. Since $K_{1}\left(t_{c}\right)=K_{2}\left(t_{c}\right)=0$ and

\footnotetext{
${ }^{3}$ For $\delta>0$, there are additional algebraic solutions if we do not impose an initial value equal to zero. These solutions generate strictly positive levels of capital at all times. Generically, capital does not even get close to zero but converges to infinity for some $t<0$.
} 
Figure 1: The Ambiguous Evolution of Capital.

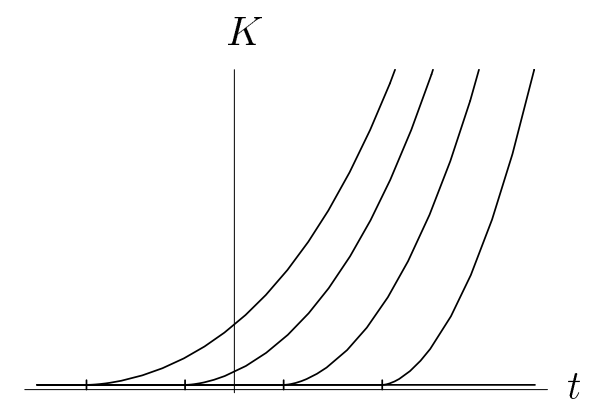

All trajectories qualify as possible evolutions of capital. The later the take-off, the steeper is the trajectory for $t>t_{c}$.

$\dot{K}_{1}\left(t_{c}\right)=\dot{K}_{2}\left(t_{c}\right)=0$, the path of capital is not unique at each critical date $t_{c}$ : capital is zero before $t_{c}$ and may either follow $K_{1}(t)$ or $K_{2}(t)$ after $t_{c}$. We may interpret $t_{c}$ as the moment of a take-off and conclude that the solution to the differential equation (3) may take off at any time $t_{c}$, or never (see Figure 1).

The behavior following the take-off is determined by the level of population at that time. If capital takes off late and $n>0$, then the capital stock grows faster because its population is larger. For large $t, K_{1}(t)$ becomes approximately proportional to $e^{n \beta t /(1-\alpha)}$. Hence, the asymptotic growth rate of capital is $n \beta /(1-\alpha)$. For the trivial solution $K_{2}(t)$, the growth rate is ill-defined.

The fact that the evolution of capital is not unique for $K=0$ is linked to the missing Lipschitz continuity of the differential equation. A differential equation $\dot{K}=f(K, t)$ is said to satisfy the Lipschitz condition if $\left|f(K, t)-f\left(K^{\prime}, t\right)\right|<L\left|K-K^{\prime}\right|$ within the definition interval for some finite constant $L$ (see, e.g., Aliprantis and Border (1998)). In particular, when $\partial f(K, t) / \partial K=\infty$ for some $K$ and $t$, the differential equation cannot be Lipschitz continuous at this point since differentiability implies Lipschitz continuity. We know from Picard's Existence Theorem that a solution to a differential equation is unique if the equation is Lipschitz continuous. Here, the 
test for Lipschitz continuity fails,

$$
\lim _{K(t) \rightarrow 0} \frac{\partial \dot{K}(t)}{\partial K(t)}=\lim _{K(t) \rightarrow 0} \frac{s A \alpha e^{n \beta t}}{K(t)^{1-\alpha}}-\delta=\infty .
$$

Since $e^{n \beta t}$ is always positive, the fraction is unbounded for small $K(t)$.

Thus, contrary to the common perception in the literature (see the quotes given in the Introduction), the basic conclusion of this section is that the economy with zero capital at some time may either go on without accumulation forever or depart on a trajectory with positive growth of the capital stock, albeit with no cause. No first piece of capital is needed to trigger accumulation initially. The take-off happens spontaneously.

\section{Essentiality and the Inada Condition}

We now turn to more general production functions. Our central finding is the following theorem.

Theorem Consider the equation of motion (2) with $Y(t)=F(K(t), L(t))$, where $F \in \mathcal{C}^{2}\left(\mathbb{R}_{+}^{2}\right)$ is strictly concave in $K$. Let $K\left(t_{c}\right)=0$ at some time $t_{c}$. Then,

1. if $F(0, L)=0$ and $\lim _{K \rightarrow 0} \partial F / \partial K=\infty$, then the evolution of capital is not unique: capital takes off spontaneously at some $t \geq t_{c}$ or remains at zero;

2. if $F(0, L)=0$ and $\lim _{K \rightarrow 0} \partial F / \partial K<\infty$, capital remains at zero;

3. if $F(0, L)>0$, capital takes off immediately.

Proof. Since the proof of the non-uniqueness result stated under Case 1 of the theorem is technically involved, it is relegated to an Appendix. The remainder of the proof is given in the main text below. 
According to Case 1, a spontaneous take-off may occur for quite general production functions if capital is essential and the Inada condition is satisfied. An intuitive explanation of this result is as follows.

If $F(0, L)=0$, then capital is essential and the trivial solution always satisfies the equation of motion: $K=0$ for all $t$ implies $\dot{K}=s F(K, L)-\delta K=s F(0, L)=0$. The Inada condition for capital requires $\lim _{K \rightarrow 0} \partial F / \partial K=\infty$. It is usually imposed to exclude a stable trivial steady state. What matters here can be seen from the derivative of the equation of motion (2) with respect to $K$ and its limit

$$
\frac{\partial \dot{K}}{\partial K}=s \frac{\partial F}{\partial K}-\delta, \quad \text { and } \quad \lim _{K \rightarrow 0} \frac{\partial \dot{K}}{\partial K}=s \lim _{K \rightarrow 0} \frac{\partial F}{\partial K}-\delta .
$$

Due to the Inada condition, $\partial \dot{K} / \partial K$ converges to infinity for small $K$. As a result, the differential equation is not Lipschitz continuous at $K=0$, and its solution need not be unique. In the technical appendix we strengthen this result and prove that the solution to (2) in fact is not unique. Thus, although capital is essential, there must be solutions that spontaneously take off from zero.

Intuitively, this ambiguity arises from two opposing forces that affect the equation of motion at $K=0$. On the one hand, no capital can be accumulated since capital is essential. On the other hand, the marginal product of capital is infinite. Roughly speaking, even a zero amount of capital can lead to positive output, and thereupon to accumulation. Which of these forces dominates at each date $t_{c}$ is unpredictable. Either the essentiality of capital dominates and produces the trivial solution, i. e. capital remains zero, or the Inada condition gets the upper hand and triggers an instantaneous take-off.

It is worth noting that the property of constant returns to scale in conjunction with the Inada condition implies essentiality (see, e.g. Barro and Sala-í-Martin (2004, p. 77)). Hence, we have the following corollary.

Corollary Consider the assumptions of the theorem. If $F$ is a neoclassical production function, then capital may take off spontaneously at any time $t$ or remain at zero. 
In Case 2, $F$ violates the Inada condition. Accordingly, the equation of motion is Lipschitz continuous; its solution is unique. Since essentiality implies $\dot{K}=0$, a takeoff is excluded. Case 3 states that a take-off must occur if capital is not essential. Here, however, the take-off is not spontaneous, but due to a strictly positive amount of investment.

The role of essentiality and the Inada condition can be illustrated for the CES production function $F(K, L)=\left[a(b K)^{\psi}+(1-a)((1-b) L)^{\psi}\right]^{1 / \psi}$, where $\psi<$ 1 determines the elasticity of substitution between capital and labor. Capital is essential for $\psi \leq 0$, i. e. for a sufficient degree of complementarity. Moreover, the Inada condition holds for $0 \leq \psi<1$. Hence, Case 1 of the Theorem only applies for $\psi=0$; the production function is Cobb-Douglas. For $\psi<0$, Case 2 applies, i. e. if capital is ever zero, it stays there. For $\psi>0$, the production function satisfies the Inada condition, yet capital is not essential. According to Case 3, if capital is zero, it takes off instantaneously. Somewhat paradoxically, the analysis of the "trivial" steady state is most complex for the textbook example involving a Cobb-Douglas technology.

We may use the CES example to build intuition for the two algebraic solutions $K_{1}(t)$ and $K_{2}(t)$ that we derived in Section 2 for the Cobb-Douglas case. For $\psi<0$ the only solution to the differential equation (2) is the trivial solution $K=0$. Since the Cobb-Douglas function obtains as the limit of the CES as $\psi \rightarrow 0$ from below, it is quite intuitive that in the limit $K_{2}(t)$ obtains as a solution, and the economy may not take off. For $\psi>0$, the differential equation (2) exhibits an immediate take-off. Now, consider the Cobb-Douglas as a limit of the CES as $\psi \rightarrow 0$ from above. In the limit, the solution $K_{1}(t)$ preserves the property of an immediate take-off. Thus, from a CES viewpoint both solutions $K_{1}(t)$ and $K_{2}(t)$ have intuitive appeal. ${ }^{4}$

\footnotetext{
${ }^{4}$ An alternative intuition for $K_{1}(t)$ and $K_{2}(t)$ starts from the discrete-time difference equation $K(t+\Delta t)-K(t)=\left(s A K(t)^{\alpha} e^{n \beta t}-\delta K(t)\right) \Delta t$, with the initial value $K\left(t_{c}\right)>0$. Then, one finds that $\lim _{K\left(t_{c}\right) \rightarrow 0} \lim _{\Delta t \rightarrow 0} K(t)=K_{1}(t)$, but $\lim _{\Delta t \rightarrow 0} \lim _{K\left(t_{c}\right) \rightarrow 0} K(t)=K_{2}(t)$. In other words, the order of the limits determines whether $K_{1}(t)$ or $K_{2}(t)$ obtains. If the differential equation were
} 
Observe that the intuition behind the Theorem can be used to allow for a spontaneous take-off from a state with strictly positive output. To see this, replace the equation of motion (2) by $\dot{K}=g(K)-\delta K$, where $g(K)$ relates aggregate output to gross investment. Denote $\bar{K}$ the initial amount of agricultural capital, and let $\bar{K}$ satisfy $g(\bar{K})=\delta \bar{K}$. Then, the economy is initially in a stationary state with positive output, savings, and investment. If in addition $g^{\prime}(\bar{K})=\infty$, then the economy may either stay in the stationary state forever or take off.

\section{Concluding Remarks}

The purpose of this paper is not to delve into the metaphysics of capital accumulation or into the origin of economic live. Rather, it aims at a complete understanding of the dynamics of the seminal growth model of Solow (1956) and Swan (1956). For a broad class of production functions, encompassing the neoclassical production function, we show that the evolution of an economy devoid of capital cannot be unique. The economy may either take off at any date or remain without capital forever.

The explanation of this paradoxical feature relies on the subtle interaction of two common assumptions. As we have shown, essentiality alone precludes a take-off, and the Inada-condition alone implies an immediate take-off. Yet, when both properties hold, a take-off is possible, but need not happen. These findings suggest that the zero-capital state of the neoclassical growth model is not necessarily steady, and by no means trivial.

Lipschitz continuous, then the limit of the solution would be unique and independent of the order of the limits. 


\section{A Proof of Case 1 of the Theorem}

This appendix establishes the non-uniqueness result stated in Case 1 of the Theorem. To accomplish this, we proceed in two steps, each comprising the proof of a Lemma. Without loss of generality, we set $t_{c}=0$.

Lemma 1 Assume that the solution of (2) at $K=0$ is not unique for a production function $F(K, L)$. Then, for a production function $G(K, L) \in \mathcal{C}^{2}\left(\mathbb{R}_{+}^{2}\right)$ satisfying $G(0, L)=0$ and $G(K, L)>F(K, L)$ in a neighborhood of $K=0$ and some $L>0$, the solution to (2) is not unique either.

Proof of Lemma 1: As $G(K, L)>F(K, L)$ in the neighborhood $K \in(0 ; \bar{K})$, the lefthand side of (2) is greater with the production function $G$ than with $F$. Accordingly, for any $K \in(0 ; \bar{K}), K$ evolves faster under technology $G$.

Consider the non-trivial solution $K_{1}$ under the production function $F$. Denote $\bar{t}$ the point in time for which $K_{1}(\bar{t})=\bar{K}$. Next, consider (2) with production technology $G$, and let $K_{G}(t)$ be the solution of the associated initial value problem where $K_{G}(\bar{t})=\bar{K}$. Since $\dot{K}_{G}>\dot{K}_{1}$ for any $K>0$, moving backwards in time reveals that there is a time $t_{G} \in[0, \bar{t})$ such that $K_{G}\left(t_{G}\right)=0$. Hence, starting from $t_{G}$ under technology $G$, capital may take off.

Finally, essentiality implies that $K=0$ is another solution describing the evolution under the production function $G$. Hence, there are at least two solutions.

In the following lemma, we show that for any strictly concave production function $G(K, L)$ satisfying the Inada condition and essentiality of capital, one can find a Cobb-Douglas production function $F(K, L)=A K^{\alpha} L^{1-\alpha}$ with $G(K, L)>F(K, L)$ in a neighborhood of $K=0$. To reduce clutter, we shall suppress the argument $L$ such that $G(K, L)$ simplifies to $G(K)$ and $F(K)=\gamma K^{\alpha}$, where $\gamma>0$ is a summary statistic of units and labor input. 
Lemma 2 Let $G \in \mathcal{C}^{2}\left(\mathbb{R}_{+}\right)$be a strictly concave production function with $G(0)=0$ and $G^{\prime}(0)=\infty$. Then, there are parameters $\gamma>0, \alpha \in(0 ; 1)$, and $\bar{K}>0$ such that $G(K)>F(K)=\gamma K^{\alpha}$ for all $K \in(0 ; \bar{K})$.

Proof of Lemma 2 (by contradiction): Assume a function $G(K)$ with the abovementioned properties. Suppose there is no Cobb-Douglas function $F(K)=\gamma K^{\alpha}$ with $G(K)>F(K)$ in a neighborhood of $K=0$. Consider both functions on a double logarithmic scale, i. e., let $\tilde{G}(x)=\log G(\exp x)$ and $\tilde{F}(x)=\log F(\exp x)=$ $\alpha x+\log \gamma$. By assumption, there is no $\bar{x}=\log \bar{K}$ such that $\tilde{G}(x)<\tilde{F}(x)$ for all $x \in(-\infty ; \bar{x})$. The latter is only possible if $\liminf _{x \rightarrow-\infty} \tilde{G}^{\prime}(x)=\infty$.

Back from the double-log scale to the linear scale, we have $G(K)=\exp \tilde{G}(\log K)$ and

$$
G^{\prime \prime}(K)=\frac{\exp \tilde{G}(\log K)}{K^{2}}\left[\tilde{G}^{\prime \prime}(\log K)-\tilde{G}^{\prime}(\log K)+\tilde{G}^{\prime}(\log K)^{2}\right] .
$$

$G^{\prime \prime}(K)<0$ implies $\tilde{G}^{\prime \prime}(x)-\tilde{G}^{\prime}(x)+\tilde{G}^{\prime}(x)^{2}<0$, or $\tilde{g}^{\prime}(x)-\tilde{g}(x)+\tilde{g}(x)^{2}<0$, where $\tilde{g}(x):=\tilde{G}^{\prime}(x)$. This gives rise to the differential inequality $\tilde{g}^{\prime}(x)<\tilde{g}(x)^{2}-\tilde{g}(x)$.

The solution to the associated differential equation is

$$
\tilde{g}(x)=\frac{\exp x}{1 / \tilde{g}_{0}-1+\exp x} .
$$

Since $\lim \inf _{x \rightarrow-\infty} \tilde{G}^{\prime}(x)=\infty, \tilde{g}(x)$ is not bounded above for $x \rightarrow-\infty$. Hence, at some point, $\tilde{g}(x)>1$. Consider the differential inequality with an initial value $x_{0}$ satisfying $\tilde{g}\left(x_{0}\right)>1$. For $x<x_{0}$, we obtain the inequality

$$
\tilde{g}(x) \geq \frac{\exp \left(x-x_{0}\right)}{1 / g_{0}-1+\exp \left(x-x_{0}\right)} .
$$

The solution to the differential equation becomes infinite at a finite $x=x_{0}+\log \left(\tilde{g}_{0}-\right.$ $1)-\log \left(\tilde{g}_{0}\right)$. Since this solution is a lower bound for $\tilde{g}(x)$, the latter must become infinite, too. Hence, $\tilde{G}^{\prime}(x)$ must become infinite. We arrive at contradiction to $\tilde{G}(x)$ being concave. A concave function cannot become infinite in the interior.

Hence, parameters $\gamma$ and $\alpha$ exist, such that there is a Cobb-Douglas function below $G(K)$. The solution to the differential equation (2) is necessarily non-unique. 


\section{References}

Aliprantis, C. D., And K. C. Border (1998): Infinite Dimensional Analysis. Springer-Verlag, Berlin et al.

Barro, R. J., And X. SAla-Í-Martin (2004): Economic Growth. MIT Press, Cambridge, MA, 2nd edn.

Gandolfo, G. (1997): Economic Dynamics - Study Edition. Springer Verlag, Berlin - Heidelberg.

Hakenes, H., And A. Irmen (2005): "Neoclassical Growth and the "Trivial" Steady State," CEPR Discussion Paper No. 4943.

Harris, J. R., ANd M. P. Todaro (1970): "Migration, Unemployment, and

Development: A Two-Sector Analysis," American Economic Review, 60, 126-142.

InADA, K.-I. (1963): "On Two-Sector Models of Economic Growth: Comments and a Generalization," Review of Economic Studies, 30, 119-127.

Kremer, M. (1993): "Population Growth and Technical Change: One Million B. C. to 1990," Quarterly Journal of Economics, 108(3), 681-716.

Mankiw, N. G., D. Romer, and D. N. Weil (1992): "A Contribution to the Empirics of Economic Growth," Quarterly Journal of Economics, 107(2), 407-437.

Romer, D. (2006): Advanced Macroeconomics. McGraw Hill, New York, 3nd edn.

Solow, R. M. (1956): "A Contribution to the Theory of Economic Growth," Quarterly Journal of Economics, 70(1), 65-94.

Swan, T. W. (1956): "Economic Growth and Capital Accumulation," Economic Record, 32, 334-361. 


\section{CESifo Working Paper Series}

(for full list see www.cesifo-group.de)

1609 Kai A. Konrad and Wolfgang Leininger, The Generalized Stackelberg Equilibrium of the All-Pay Auction with Complete Information, November 2005

1610 Monika Buetler and Federica Teppa, Should you Take a Lump-Sum or Annuitize? Results from Swiss Pension Funds, November 2005

1611 Alexander W. Cappelen, Astri D. Hole, Erik Ø. Sørensen and Bertil Tungodden, The Pluralism of Fairness Ideals: An Experimental Approach, December 2005

1612 Jack Mintz and Alfons J. Weichenrieder, Taxation and the Financial Structure of German Outbound FDI, December 2005

1613 Rosanne Altshuler and Harry Grubert, The Three Parties in the Race to the Bottom: Host Governments, Home Governments and Multinational Companies, December 2005

1614 Chi-Yung (Eric) $\mathrm{Ng}$ and John Whalley, Visas and Work Permits: Possible Global Negotiating Initiatives, December 2005

1615 Jon H. Fiva, New Evidence on Fiscal Decentralization and the Size of Government, December 2005

1616 Andzelika Lorentowicz, Dalia Marin and Alexander Raubold, Is Human Capital Losing from Outsourcing? Evidence for Austria and Poland, December 2005

1617 Aleksander Berentsen, Gabriele Camera and Christopher Waller, Money, Credit and Banking, December 2005

1618 Egil Matsen, Tommy Sveen and Ragnar Torvik, Savers, Spenders and Fiscal Policy in a Small Open Economy, December 2005

1619 Laszlo Goerke and Markus Pannenberg, Severance Pay and the Shadow of the Law: Evidence for West Germany, December 2005

1620 Michael Hoel, Concerns for Equity and the Optimal Co-Payments for Publicly Provided Health Care, December 2005

1621 Edward Castronova, On the Research Value of Large Games: Natural Experiments in Norrath and Camelot, December 2005

1622 Annette Alstadsæter, Ann-Sofie Kolm and Birthe Larsen, Tax Effects, Search Unemployment, and the Choice of Educational Type, December 2005

1623 Vesa Kanniainen, Seppo Kari and Jouko Ylä-Liedenpohja, Nordic Dual Income Taxation of Entrepreneurs, December 2005 
1624 Lars-Erik Borge and Linn Renée Naper, Efficiency Potential and Efficiency Variation in Norwegian Lower Secondary Schools, December 2005

1625 Sam Bucovetsky and Andreas Haufler, Tax Competition when Firms Choose their Organizational Form: Should Tax Loopholes for Multinationals be Closed?, December 2005

1626 Silke Uebelmesser, To go or not to go: Emigration from Germany, December 2005

1627 Geir Haakon Bjertnæs, Income Taxation, Tuition Subsidies, and Choice of Occupation: Implications for Production Efficiency, December 2005

1628 Justina A. V. Fischer, Do Institutions of Direct Democracy Tame the Leviathan? Swiss Evidence on the Structure of Expenditure for Public Education, December 2005

1629 Torberg Falch and Bjarne Strøm, Wage Bargaining and Political Strength in the Public Sector, December 2005

1630 Hartmut Egger, Peter Egger, Josef Falkinger and Volker Grossmann, International Capital Market Integration, Educational Choice and Economic Growth, December 2005

1631 Alexander Haupt, The Evolution of Public Spending on Higher Education in a Democracy, December 2005

1632 Alessandro Cigno, The Political Economy of Intergenerational Cooperation, December 2005

1633 Michiel Evers, Ruud A. de Mooij and Daniel J. van Vuuren, What Explains the Variation in Estimates of Labour Supply Elasticities?, December 2005

1634 Matthias Wrede, Health Values, Preference Inconsistency, and Insurance Demand, December 2005

1635 Hans Jarle Kind, Marko Koethenbuerger and Guttorm Schjelderup, Do Consumers Buy Less of a Taxed Good?, December 2005

1636 Michael McBride and Stergios Skaperdas, Explaining Conflict in Low-Income Countries: Incomplete Contracting in the Shadow of the Future, December 2005

1637 Alfons J. Weichenrieder and Oliver Busch, Artificial Time Inconsistency as a Remedy for the Race to the Bottom, December 2005

1638 Aleksander Berentsen and Christopher Waller, Optimal Stabilization Policy with Flexible Prices, December 2005

1639 Panu Poutvaara and Mikael Priks, Violent Groups and Police Tactics: Should Tear Gas Make Crime Preventers Cry?, December 2005

1640 Yin-Wong Cheung and Kon S. Lai, A Reappraisal of the Border Effect on Relative Price Volatility, January 2006 
1641 Stefan Bach, Giacomo Corneo and Viktor Steiner, Top Incomes and Top Taxes in Germany, January 2006

1642 Johann K. Brunner and Susanne Pech, Optimum Taxation of Life Annuities, January 2006

1643 Naércio Aquino Menezes Filho, Marc-Andreas Muendler and Garey Ramey, The Structure of Worker Compensation in Brazil, with a Comparison to France and the United States, January 2006

1644 Konstantinos Angelopoulos, Apostolis Philippopoulos and Vanghelis Vassilatos, RentSeeking Competition from State Coffers: A Calibrated DSGE Model of the Euro Area, January 2006

1645 Burkhard Heer and Bernd Suessmuth, The Savings-Inflation Puzzle, January 2006

1646 J. Stephen Ferris, Soo-Bin Park and Stanley L. Winer, Political Competition and Convergence to Fundamentals: With Application to the Political Business Cycle and the Size of Government, January 2006

$1647 \mathrm{Yu}-\mathrm{Fu}$ Chen, Michael Funke and Kadri Männasoo, Extracting Leading Indicators of Bank Fragility from Market Prices - Estonia Focus, January 2006

1648 Panu Poutvaara, On Human Capital Formation with Exit Options: Comment and New Results, January 2006

1649 Anders Forslund, Nils Gottfries and Andreas Westermark, Real and Nominal Wage Adjustment in Open Economies, January 2006

1650 M. Hashem Pesaran, Davide Pettenuzzo and Allan G. Timmermann, Learning, Structural Instability and Present Value Calculations, January 2006

1651 Markku Lanne and Helmut Luetkepohl, Structural Vector Autoregressions with Nonnormal Residuals, January 2006

1652 Helge Berger, Jakob de Haan and Jan-Egbert Sturm, Does Money Matter in the ECB Strategy? New Evidence Based on ECB Communication, January 2006

1653 Axel Dreher and Friedrich Schneider, Corruption and the Shadow Economy: An Empirical Analysis, January 2006

1654 Stefan Brandauer and Florian Englmaier, A Model of Strategic Delegation in Contests between Groups, January 2006

1655 Jan Zápal and Ondřej Schneider, What are their Words Worth? Political Plans and Economic Pains of Fiscal Consolidations in New EU Member States, January 2006

1656 Thiess Buettner, Sebastian Hauptmeier and Robert Schwager, Efficient Revenue Sharing and Upper Level Governments: Theory and Application to Germany, January 2006 
1657 Daniel Haile, Abdolkarim Sadrieh and Harrie A. A. Verbon, Cross-Racial Envy and Underinvestment in South Africa, February 2006

1658 Frode Meland and Odd Rune Straume, Outsourcing in Contests, February 2006

1659 M. Hashem Pesaran and Ron Smith, Macroeconometric Modelling with a Global Perspective, February 2006

1660 Alexander F. Wagner and Friedrich Schneider, Satisfaction with Democracy and the Environment in Western Europe - a Panel Analysis, February 2006

1661 Ben J. Heijdra and Jenny E. Ligthart, Fiscal Policy, Monopolistic Competition, and Finite Lives, February 2006

1662 Ludger Woessmann, Public-Private Partnership and Schooling Outcomes across Countries, February 2006

1663 Topi Miettinen and Panu Poutvaara, Political Parties and Network Formation, February 2006

1664 Alessandro Cigno and Annalisa Luporini, Optimal Policy Towards Families with Different Amounts of Social Capital, in the Presence of Asymmetric Information and Stochastic Fertility, February 2006

1665 Samuel Muehlemann and Stefan C. Wolter, Regional Effects on Employer Provided Training: Evidence from Apprenticeship Training in Switzerland, February 2006

1666 Laszlo Goerke, Bureaucratic Corruption and Profit Tax Evasion, February 2006

1667 Ivo J. M. Arnold and Jan J. G. Lemmen, Inflation Expectations and Inflation Uncertainty in the Eurozone: Evidence from Survey Data, February 2006

1668 Hans Gersbach and Hans Haller, Voice and Bargaining Power, February 2006

1669 Françoise Forges and Frédéric Koessler, Long Persuasion Games, February 2006

1670 Florian Englmaier and Markus Reisinger, Information, Coordination, and the Industrialization of Countries, February 2006

1671 Hendrik Hakenes and Andreas Irmen, Something out of Nothing? Neoclassical Growth and the 'Trivial' Steady State, February 2006 